Relationship between changes in BMD and nonvertebral fracture incidence associated with risedronate: Reduction in risk of nonvertebral fracture is not related to change in BMD

Peer-reviewed author version

Watts, N.B.; GEUSENS, Piet; Barton, I. \& Felsenberg, D. (2005) Relationship between changes in BMD and nonvertebral fracture incidence associated with risedronate: Reduction in risk of nonvertebral fracture is not related to change in BMD. In: JOURNAL OF BONE AND MINERAL RESEARCH, 20(12). p. 2097-2104.

DOI: 10.1359/JBMR.050814

Handle: http://hdl.handle.net/1942/1005 


\title{
Relationship Between Changes in BMD and Nonvertebral Fracture Incidence Associated With Risedronate: Reduction in Risk of Nonvertebral Fracture Is Not Related to Change in BMD
}

\author{
Nelson B Watts, ${ }^{1}$ Piet Geusens, ${ }^{2}$ Ian P Barton, ${ }^{3}$ and Dieter Felsenberg ${ }^{4}$
}

\begin{abstract}
Whether greater treatment-related changes in BMD result in greater decreases in fracture risk is controversial. We analyzed the relationship between BMD change and nonvertebral fracture risk in postmenopausal osteoporotic women from the risedronate fracture program. Change in BMD did not influence the magnitude of risedronate's effect on nonvertebral fractures; the incidence of nonvertebral fractures was equally low in treated patients whose BMD increased or decreased.
\end{abstract}

Introduction: In untreated patients, low BMD correlates with increased fracture risk. Whether greater increases in BMD induced by anti-osteoporosis drugs are related to greater decreases in vertebral fracture risk is controversial, and little has been written about the relationship between change in BMD and nonvertebral fracture risk. We analyzed the relationship between BMD change and nonvertebral fracture incidence using individual patient data from postmenopausal osteoporotic women receiving antiresorptive treatment with risedronate.

Materials and Methods: This posthoc analysis combined data from three pivotal risedronate fracture endpoint trials. Women received risedronate 2.5 or $5 \mathrm{mg}(n=2561)$ or placebo $(n=1418)$ daily for up to 3 years. BMD and nonvertebral fractures confirmed by radiograph (hip, wrist, pelvis, humerus, clavicle, and leg) were assessed periodically over 3 years.

Results: The incidence of nonvertebral fractures in risedronate-treated patients was not different between patients whose spine BMD decreased (7.8\%) and those whose spine BMD increased (6.4\%; hazard ratio to subgroup of patients who lost BMD [HR], 0.79; 95\% CI, 0.50, 1.25) or between those whose femoral neck BMD decreased (7.6\%) and those whose femoral neck BMD increased (7.5\%; HR, 0.93; 95\% CI, 0.68, 1.28). The changes in lumbar spine and femoral neck BMD explained only $12 \%(95 \%$ CI, $2 \%, 21 \% ; p=0.014)$ and $7 \%(95 \%$ CI, $2 \%, 13 \% ; p=0.005)$, respectively, of risedronate's nonvertebral fracture efficacy.

Conclusions: For patients treated with risedronate, changes in BMD as measured by DXA do not predict the degree of reduction in nonvertebral fractures.

J Bone Miner Res 2005;20:2097-2104. Published online on August 8, 2005; doi: 10.1359/JBMR.050814

Key words: bone mass, nonvertebral fractures, risedronate, surrogate measure, osteoporosis

\section{INTRODUCTION}

$\mathrm{O}$ STEOPOROSIS IS A skeletal disorder characterized by compromised bone strength that predisposes affected persons to an increased risk of fracture. ${ }^{(1)}$ Over 10 million people have osteoporosis in the United States, ${ }^{(2)}$ and the

Mr Barton is an employee of Procter \& Gamble. Dr Felsenberg serves as a consultant for Eli Lilly and Company, GlaxoSmithKline, Merck \& Co., Novartis, Nycomed, Procter \& Gamble, Roche, and Schering. Dr Watts received honoraria from Aventis, Merck \& Co., and Procter \& Gamble, serves as a consultant for Aventis, Eli Lilly and Company, GlaxoSmithKline, Merck \& Co., Novartis, NPS Pharmaceuticals, Procter \& Gamble, Roche, Servier, and Wyeth, and receives funding through his university from Amgen, Aventis, Eli Lilly and Company, Merck \& Co., Novartis, and Procter \& Gamble. All other authors have no conflict of interest. risk of fracture is high among these individuals. For a 50year-old white woman, the remaining lifetime risk of fracture of the spine, hip, or distal forearm is estimated to be about $40 \% .{ }^{(3)}$ Because fracture is the most important event in osteoporosis, ${ }^{(4)}$ the primary goal of treatment is to reduce the risk of fracture. ${ }^{(5)}$ Although head-to-head trials of antiresorptive agents with fracture as the primary endpoint would be ideal, such trials are a tremendous undertaking, requiring a large patient population and a lengthy duration. ${ }^{(6)}$ As a consequence, surrogate measures of fracture risk, such as BMD as determined with DXA, in which changes can be shown in smaller, shorter studies, have been proposed to assess the efficacy of available osteoporosis treatments. ${ }^{(7)}$

The validity of using change in BMD to infer the effect of antiresorptive treatment on reduction in vertebral frac-

${ }^{1}$ University of Cincinnati Bone Health and Osteoporosis Center, Cincinnati Ohio, USA; ${ }^{2}$ Limburgs Universitair Centrum, Diepenbeek, Belgium and Department of Rheumatology, University Hospital, Maastricht, The Netherlands; ${ }^{3}$ Procter \& Gamble Pharmaceuticals, Mason, Ohio, USA; ${ }^{4}$ Free University Berlin, University Hospital Benjamin Franklin, Centre of Muscle and Bone Research, Berlin, Germany. 
ture risk has been a topic of much debate over the last decade. ${ }^{(8-12)}$ Meta-analyses performed by several groups in an attempt to resolve this issue have produced conflicting results. Some investigators have concluded that larger increases in BMD in women treated with antiresorptive agents are associated with a lower risk of new morphometric vertebral fractures, ${ }^{(9,13,14)}$ whereas others have concluded that greater increases in BMD do not predict greater decreases in morphometric vertebral fracture risk. ${ }^{(10,15-19)}$

BMD measured by DXA is a measure of areal density. Areal density is the product of the physical density and the total thickness of the attenuating material, ${ }^{(20)}$ and is, in physical terms, the total mass in a column of unit crosssectional area. ${ }^{(20)}$ This is only one of many factors that contribute to bone's resistance to fracture. The changes in BMD during antiresorptive treatment occur at least in part because of changes in mineralization, a material property of the bone matrix. Changes in BMD do not necessarily represent changes in other properties that may determine resistance of bone to fracture, such as microarchitecture, geometry, activation frequency, and remodeling rate. Therefore, it seems unlikely that changes in BMD as measured by DXA would explain all of the reduction in fracture risk induced by drug treatment.

Although much has been written about the relationship between change in BMD and vertebral fractures, ${ }^{8,9,11-18)}$ few studies have analyzed the relationship between change in BMD and nonvertebral fractures, and those have yielded conflicting results. Hochberg et al. ${ }^{(21)}$ found a relationship between changes in BMD during the first year of antiresorptive treatment and reduction in the incidence of nonvertebral fractures occurring over the duration of studies using meta-analyses based on summary data at the trial level. It is well documented that the results of metaanalyses based on summary data can differ markedly from those based on individual patient data. ${ }^{(22,23)}$ Individual patient data provide the most comprehensive information, and it has been suggested that such analysis should be the basis for statistical analysis when exploring the underlying relationship. ${ }^{(11,23)}$ Using this technique, Bauer et al. ${ }^{(19)}$ did not find a significant relationship between changes in BMD (in spine or hip) during the first year of treatment with alendronate and subsequent reduction in nonvertebral fractures.

We performed a posthoc analysis of individual patient data from risedronate phase III clinical trials with a fracture endpoint $^{(24-26)}$ to examine the relationship between treatment-related change in BMD and reduction in the incidence of nonvertebral fractures.

\section{MATERIALS AND METHODS}

\section{Study design}

We combined data from three randomized, double-blind, placebo-controlled, parallel group, phase III clinical studies conducted in parallel: the Vertebral Efficacy with Risedronate Therapy North America (VERT-NA) and Multinational (VERT-MN) clinical studies and the Hip Intervention Program (HIP) study. These three studies were used because they were the pivotal risedronate fracture endpoint trials and used the same methodology for assessing incident nonvertebral fractures. In all three studies, women received risedronate $2.5 \mathrm{mg}$, risedronate $5 \mathrm{mg}$, or placebo daily for up to 3 years. All patients received calcium $1000 \mathrm{mg} /$ day, and patients whose serum 25-hydroxyvitamin D levels were $<40 \mathrm{nM}$ also received up to 500 IU vitamin D daily. All studies were conducted according to the Declaration of Helsinki and approved by the appropriate ethics committee. All patients gave written informed consent. The sponsor designed this study and analyzed the data. The study designs, patients studied, and methods are described elsewhere. ${ }^{(24-26)}$

\section{Measurements}

BMD of the lumbar spine and femoral neck was measured by DXA at baseline and at 6-month intervals at all trial centers in the VERT studies and in a subset of 44 of the 183 centers in the HIP study. Scans were analyzed at a central location for each trial.

As planned per protocol, nonvertebral fracture data were extracted from adverse event information that was collected at the study visits made every 3 months during the trials. The investigators recorded adverse events reported by the patients, as well as adverse events observed on examination of the patient. At each visit, patients were asked if they had experienced any changes in their well-being and whether they had been hospitalized or had any accidents, and a review of systems and/or physical examination was performed as required. Nonvertebral fractures were defined prospectively as fractures of the hip, wrist, pelvis, humerus, clavicle, and leg without regard for trauma. All fractures were confirmed radiographically.

\section{Statistical analysis}

The analysis population included patients who were randomized, received at least one dose of study treatment, and had both baseline and follow-up BMD measurements at either the lumbar spine or femoral neck. Data from the risedronate 2.5- and 5-mg treatment groups were combined to increase the power of the analysis and to provide a large range of BMD changes.

Descriptive statistics were generated, and the severity of osteoporosis at baseline was compared between the placebo and risedronate treatment groups.

The percent change from baseline to endpoint (last follow-up value) for lumbar spine and femoral neck BMD was calculated for each patient. The 3-year nonvertebral fracture status (i.e., whether the patient had at least one incident nonvertebral fracture) was also determined for each patient. Time to the first nonvertebral fracture was defined as the scheduled 3-monthly visit closest to the onset date of the adverse event.

The relationship between changes in BMD and the incidence of nonvertebral fractures was explored in patients taking risedronate as follows: patients were divided into 10 equal subgroups (deciles) on the basis of their change in BMD. The proportion of patients in each subgroup who sustained at least one incident nonvertebral fracture was 
plotted, and a "smoothing" curve was fitted through the data. Next, two subgroups of patients were constructed on the basis of changes in BMD: those who had a decrease in BMD (change in BMD $<0 \%$ ) and those who did not (change in $\mathrm{BMD} \geq 0 \%$ ). For each of these subgroups, the cumulative incidence of nonvertebral fractures during 3 years was calculated with Kaplan-Meier methodology, consistent with the prospectively planned statistical analyses for the three studies. The estimated risk of sustaining at least one incident nonvertebral fracture was compared between patients whose BMD increased and those whose BMD decreased using Cox regression. These analyses were also conducted on the basis of data from the VERT fracture and the HIP fracture clinical programs individually. The relationship between change in BMD (as a continuous covariate) and nonvertebral fracture risk was further characterized for risedronate-treated patients using a Cox regression model. In addition, a sensitivity analysis was performed that plotted the change in BMD during the first year of treatment against the incidence of nonvertebral fractures that occurred after the first year of treatment.

The proportion of the treatment effect of risedronate (defined as the difference between the risedronate and placebo groups) on nonvertebral fracture that was explained by changes in BMD was estimated using a published method proposed by Li et al., ${ }^{(27)}$ who were employees of the sponsor. The method of $\mathrm{Li}$ et al. was an extension of a method proposed by Freedman et al. ${ }^{(28)}$ The method of Freedman et al. involves calculating a ratio of two parameter estimates from two separate models (with and without the adjustment for the surrogate). The main limitation associated with this approach is that it relies on two separate statistical models, causing large variability. The method of $\mathrm{Li}$ et al. reduces this limitation by using one statistical model comprising a binary factor for treatment group and continuous covariates for prevalent vertebral fractures and change in BMD. ${ }^{(27)}$ The estimate is obtained by calculating the ratio of the regression coefficients, where the numerator is the risk reduction explained by the surrogate, and the denominator is the overall risk reduction by treatment.

The overall treatment effect on fracture and the proportion of the effect explained by changes in BMD were estimated within one model using Cox regression; 95\% CIs and a $p$ value were calculated.

\section{RESULTS}

A total of 3979 patients in the VERT and HIP trials (1418 placebo, 2561 risedronate) had baseline and followup DXA measurements. Of these, 3290 (83\%) had paired lumbar spine BMD data, and 3884 (98\%) had paired femoral neck BMD data. The treatment groups were comparable at baseline with respect to age and severity of osteoporosis (Table 1).

Incident nonvertebral fractures were sustained by 307 patients: 138 (10.9\%, estimated cumulative incidence) in the placebo group and $169(7.7 \%)$ in the risedronate group. This reflects an estimated reduction in fracture risk in the risedronate-treated patients of $32 \%$ (hazard ratio [HR], 0.68 ; 95\% CI, 0.54, 0.85; $p<0.001)$. The incidence of non-
Table 1. Baseline Characteristics of Patients Included in THE ANALYSIS*

\begin{tabular}{|c|c|c|}
\hline Parameter & $\begin{array}{c}\text { Placebo } \\
(N=1418)\end{array}$ & $\begin{array}{l}\text { Risedronate }^{*} \\
(N=2561)\end{array}$ \\
\hline \multicolumn{3}{|l|}{ Age (years) } \\
\hline$N$ & 1418 & 2561 \\
\hline Mean (SD) & $17(7.4)$ & $72(7.3)$ \\
\hline \multicolumn{3}{|l|}{ Vertebral fractures } \\
\hline$N$ & 1386 & 2480 \\
\hline Mean (SD) & $2.2(2.39)$ & $2.3(2.50)$ \\
\hline Median & 2 & 2 \\
\hline \multicolumn{3}{|c|}{ Patients with fractures ${ }^{\ddagger}$} \\
\hline 0 & $406(29 \%)$ & $744(30 \%)$ \\
\hline $1+$ & $980(71 \%)$ & $1736(70 \%)$ \\
\hline \multicolumn{3}{|c|}{ Femoral neck BMD $\mathrm{T}$ score ${ }^{\S}$} \\
\hline$N$ & 1399 & 2531 \\
\hline Mean (SD) & $-2.4(0.78)$ & $-2.4(0.80)$ \\
\hline \multicolumn{3}{|c|}{ Lumbar spine BMD T score ${ }^{\mathrm{Tl}}$} \\
\hline$N$ & 903 & 1558 \\
\hline Mean (SD) & $-2.6(1.29)$ & $-2.6(1.33)$ \\
\hline
\end{tabular}

* Patients were included if they had both baseline and postbaseline DXA-BMD measurements. Of the 3979 patients included in the analysis, 1561 (39\%) were from the VERT-NA study, ${ }^{(24)} 977$ (25\%) were from the VERT-MN study, ${ }^{(25)}$ and 1441 (36\%) were from the HIP study. ${ }^{(26)}$

${ }^{\dagger}$ Included patients who received risedronate 2.5 or $5 \mathrm{mg}$.

* Data are presented as number and percent of patients with a history of one or more vertebral fractures at baseline, as determined on the basis of evaluable spinal radiographs taken pretreatment.

${ }^{\S}$ National Health and Nutrition Examination Survey III. ${ }^{(29)}$

"T Gender-specific $\mathrm{T}$ score, calculated using manufacturer's normative data if all four baseline vertebrae $\left(\mathrm{L}_{1}-\mathrm{L}_{4}\right)$ were deemed intact.

vertebral fractures in the risedronate group was lower than that in the placebo group across the distribution of percent changes from baseline in $\mathrm{BMD}$ at both the lumbar spine and femoral neck (Figs. 1A, 1B, 2A, and 2B).

Of the 2087 risedronate-treated patients who had available paired lumbar spine BMD data, 123 sustained an incident nonvertebral fracture. Of these, BMD increased from baseline (change from baseline in BMD $\geq 0 \%$ ) in 100 $(6.4 \pm 0.63 \%$, estimated cumulative incidence $\pm \mathrm{SE})$, whereas BMD decreased from baseline (change from baseline in $\mathrm{BMD}<0 \%)$ in $23(7.8 \pm 1.60 \%)$. Thus, the risk of nonvertebral fracture in risedronate-treated patients whose BMD decreased did not differ significantly from that in patients whose BMD increased (HR to subgroup of patients who lost DXA-BMD, 0.79; 95\% CI, 0.50, 1.25; Fig. 1B).

Similar results were observed when the relationship between treatment-related change in femoral neck BMD and fracture incidence reduction was analyzed. A total of 162 of the 2504 risedronate-treated patients who had available paired femoral neck BMD data sustained an incident nonvertebral fracture. Of these, BMD increased from baseline in $100(7.5 \pm 0.73 \%)$, whereas BMD decreased from baseline in $62(7.6 \pm 0.94 \%)$. Thus, the incidence of nonvertebral fracture in risedronate-treated patients who lost bone was not significantly different from that in patients who gained bone (HR, 0.93; 95\% CI, 0.68, 1.28; Fig. 2B).

When the relationship between treatment-related change in lumbar spine or femoral neck BMD and fracture risk was modeled on the basis of data from the 5-mg risedronate 

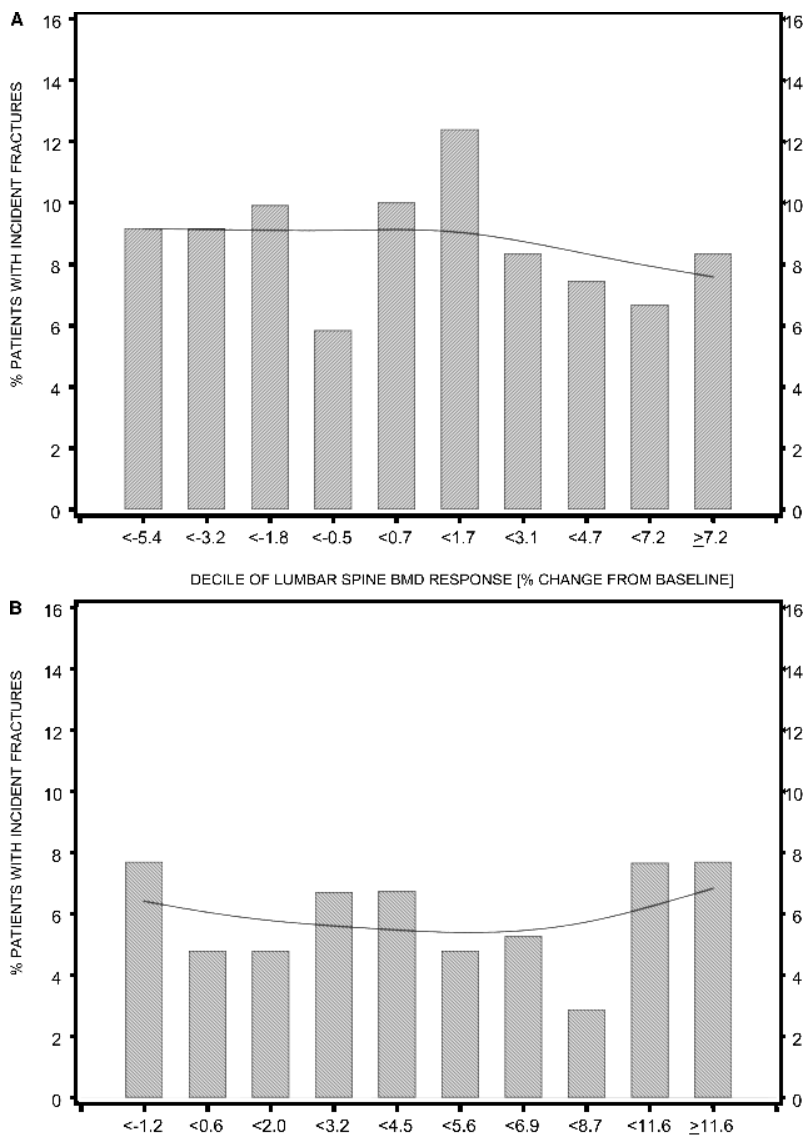

DECILE OF LUMBAR SPINE BMD RESPONSE [\% CHANGE FROM BASELINE]

FIG. 1. Relationship between the incidence of osteoporosisrelated nonvertebral fractures occurring over 3 years and increase from baseline in lumbar spine bone mass (DXA-BMD) in patients treated with $(\mathrm{A})$ placebo or $(\mathrm{B})$ risedronate 2.5 or $5 \mathrm{mg}$ by decile of percent change from baseline in BMD. (A) In the placebo group, there was an average of 120 patients in each decile, with fractures reported in 7-15 patients per decile. (B) In the risedronate group, there was an average of 209 patients in each decile, with fractures reported in 6-16 patients per decile.

group alone, similar results were observed; that is, the incidence of nonvertebral fractures was similar whether BMD from both the lumbar spine and femoral neck increased or decreased (data not shown).

Similar relationships were observed when these analyses were conducted using data from the individual VERT fracture and HIP fracture clinical programs. Although the incidence of nonvertebral fractures within the HIP program was higher than that in the VERT program, greater increases in BMD did not predict greater decreases in fracture incidence (i.e., the smoothing lines remained flat; data not shown). A Cox regression model stratified by trial and adjusting for treatment group, looking at the underlying relationship between nonvertebral fracture risk and change in BMD, did not show that the relationship differed between the trials $(p=0.379)$.

The relationship between change in BMD (as a continuous covariate) and nonvertebral fracture risk for risedronate-treated patients was characterized by HRs of $\sim 1$ for
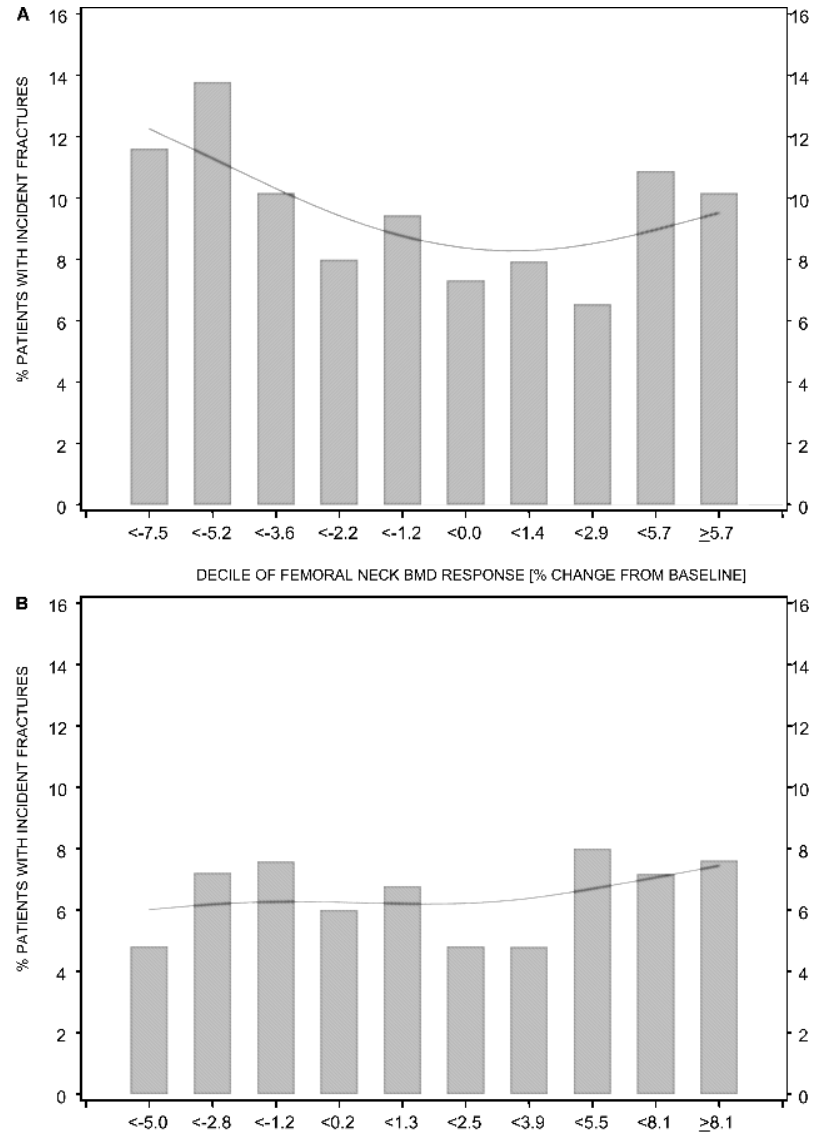

DECILE OF FEMORAL NECK BMD RESPONSE [\% CHANGE FROM BASELINE]

FIG. 2. Relationship between the incidence of osteoporosisrelated nonvertebral fractures occurring over 3 years and increase from baseline in femoral neck bone mass (DXA-BMD) in patients treated with (A) placebo or (B) risedronate 2.5 or $5 \mathrm{mg}$ by decile of percent change from baseline in BMD. (A) In the placebo group, there was an average of 138 patients in each decile, with fractures reported in 9-19 patients per decile. (B) In the risedronate group, there was an average of 250 patients in each decile, with fractures reported in 12-20 patients per decile.

both the lumbar spine and the femoral neck skeletal sites $(\mathrm{HR}=1.02[0.97,1.06]$ for the spine and HR $=1.01[0.98$, 1.05] for the femoral neck skeletal sites).

Of the 307 patients in this analysis who sustained an incident nonvertebral fracture, 109 in the placebo group and 130 in the risedronate group sustained an incident nonvertebral fracture after the first year of the trial. The sensitivity analysis, in which the change in BMD during the first year of treatment was plotted against the incidence of nonvertebral fractures after the first year of treatment, showed that the relationship was flat and similar to that described above between change in BMD and fracture incidence over the course of the entire study (Figs. 3A and 3B).

The changes in lumbar spine BMD observed in this study explained only $12 \%(95 \% \mathrm{CI}, 2 \%, 21 \% ; p=0.014)$ of the effect of risedronate (compared with placebo) on nonvertebral fracture incidence. The changes in femoral neck BMD observed in this study explained only $7 \%$ (95\% CI, 

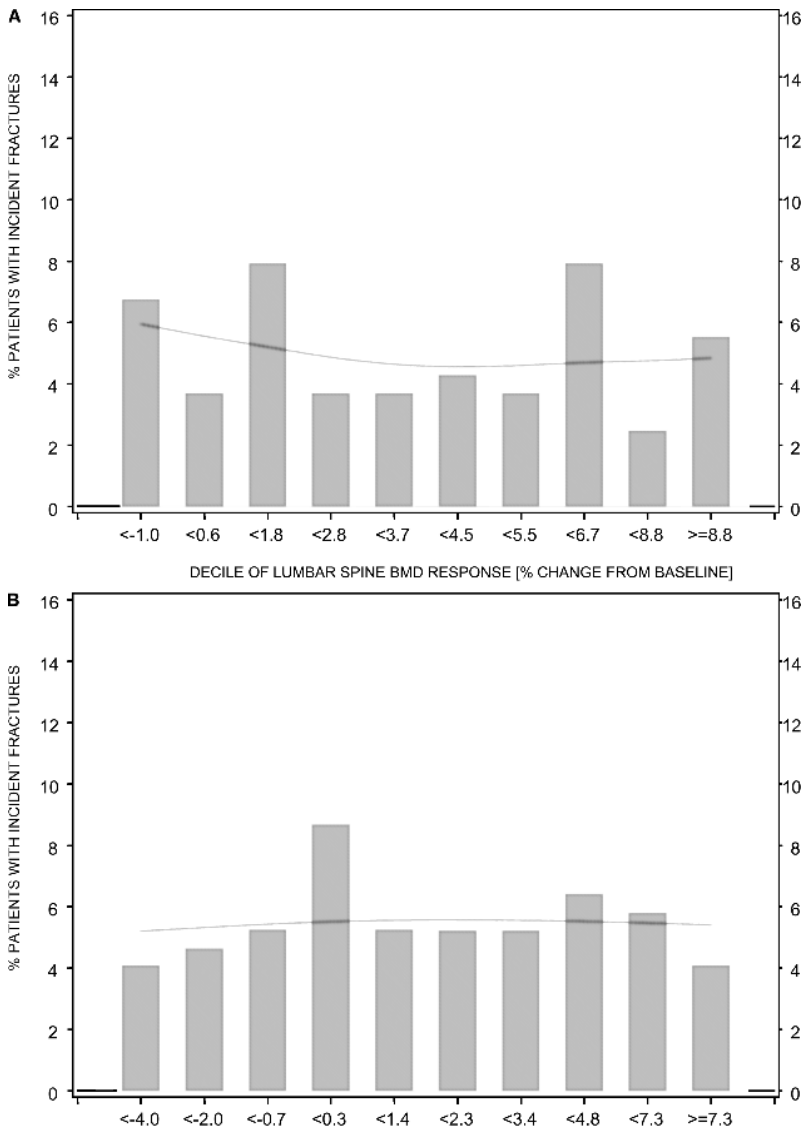

DECILE OF FEMORAL NECK BMD RESPONSE [\% CHANGE FROM BASELINE]

FIG. 3. Relationship between the incidence of osteoporosisrelated nonvertebral fractures occurring after the first year of treatment and the increase from baseline during the first year of treatment in (A) lumbar spine bone mass (DXA-BMD) in patients treated with risedronate 2.5 or $5 \mathrm{mg}$ and (B) femoral neck bone mass (DXA-BMD) in patients treated with risedronate 2.5 or $5 \mathrm{mg}$ by decile of percent change from baseline in BMD. (A) In the placebo group, there was an average of 163 patients in each decile, with fractures reported in 4-13 patients per decile. (B) In the risedronate group, there was an average of 173 patients in each decile, with fractures reported in 7-15 patients per decile.

$2 \%, 13 \% ; p=0.005)$ of the antifracture treatment effect of risedronate (compared with placebo) on nonvertebral fracture incidence.

\section{DISCUSSION}

The results of this analysis of data from the risedronate clinical trial phase III fracture programs show that greater increases in BMD are not associated with greater decreases in nonvertebral fracture incidence. These findings are consistent with the results of analyses of the relationship between changes in BMD and vertebral fractures that also showed that large increases in BMD do not predict commensurately large decreases in vertebral fracture incidence. ${ }^{(17)}$ Also, a decrease in BMD is not associated with an increased incidence of nonvertebral fractures. In this analysis, the incidence of nonvertebral fractures was similar whether BMD increased or decreased. The relationship between the BMD and nonvertebral fracture incidence was nearly flat for both lumbar spine and femoral neck BMD (Figs. 1A, 1B, 2A, 2B, 3A, and 3B); that is, the percentage of patients with nonvertebral fractures was not related to the patients' BMD response.

Our findings are consistent with those of Bauer et al. ${ }^{(19)}$ based on their analysis of individual patient data from a larger, independent database from alendronate-treated patients. Although Bauer et al. ${ }^{(19)}$ found a relationship between changes in hip BMD in the first year of alendronate treatment and subsequent vertebral fractures, they found no relationship between changes in BMD in the spine or hip during the first year of treatment and subsequent nonvertebral fracture reduction. Using a Cox regression model, they showed that the relationship between change in BMD and the risk of nonvertebral fracture for alendronatetreated patients was characterized by HRs of $\sim 1$ at the spine and total hip skeletal sites $(\mathrm{HR}=1.05[0.92,1.20]$ for the spine and HR $=1.03[0.90,1.17]$ for the total hip skeletal sites). Thus, both our analysis and the analysis of Bauer et al. provide evidence that the relationship between treatment-related changes in the incidence of nonvertebral fractures and changes in BMD is "flat."

Although these findings may seem counterintuitive, they are consistent with increasing evidence that factors other than DXA-measured BMD, such as geometry, microarchitecture, activation frequency, and material properties, are important determinants of bone strength. The difference in lumbar spine BMD observed between the two groups in this study explained only $12 \%$ of the fracture treatment effect, and the difference in femoral neck BMD explained only $7 \%$ of the fracture treatment effect, results consistent with observations on vertebral fractures. ${ }^{(17)}$

The statistical methodology used in our analysis to determine the proportion of the treatment-related reduction in nonvertebral fracture incidence that was attributable to change in BMD was an extension by $\mathrm{Li}$ et al. of methodology developed by Freedman et al., which has been used in previous research on antiresorptive treatments. ${ }^{(14,16)}$ In 1992, Freedman et al., independent of industry, proposed methodology to estimate the proportion of the treatment effect explained by a surrogate. ${ }^{(28)}$ Recently there has been disagreement about the use of the "Freedman analysis" framework to estimate the proportion of the effect of treatment on fracture that can be attributed to changes in BMD. ${ }^{(30,31)}$ However, the estimates observed in the analyses reported here and those by Watts et al. ${ }^{(17)}$ using the data from the risedronate phase III clinical trial program are similar to those observed by other investigators in their analyses of data from trials using individual patient data of two other antiresorptives. ${ }^{(14,16)}$ The results of these analyses are consistent and indicate that only a small proportion of the fracture reduction associated with raloxifene or alendronate can be attributed to the effect of treatment on BMD. Furthermore, other investigators have used an extension of Freedman's methodology to determine the proportion of treatment effect explained by a surrogate marker using individual patient data from a study on patients with essential hypertension and left ventricular hypertrophy. ${ }^{(32)}$ 
This suggests that such methodology is accepted among researchers across therapeutic areas and in different and competing industrial research institutions.

Our findings are in contrast with those of Hochberg et al. ${ }^{(21)}$ In their analyses, larger increases in BMD appeared to be associated with greater reductions in the risk of nonvertebral fractures. They found that changes in BMD during treatment seem to explain all of the reduction in the risk of nonvertebral fractures. ${ }^{(21)}$ This discrepancy is probably related to the differences in the analyses used. Hochberg et al. used meta-analyses based on summary data at the trial level for their study, ${ }^{(21)}$ whereas we used analyses based on individual patient data. Statistical analyses based on summary data and those based on individual patient data have been shown to produce different results. ${ }^{(11,22,23)}$ Metaanalyses based on group-level summary statistics (as opposed to individual patient data) model trial-level associations and not the underlying associations at the patient level. ${ }^{(9,11)}$ Therefore, trial-level covariates cannot reliably show the true relationship between these covariates and the effect of treatment at the level of the individual. In their evaluation of meta-analytic approaches, Thompson and Higgins $^{(33)}$ state that regression on summary statistics using estimates published in papers does not allow the underlying relationship to be fully understood. They observed that, although summary statistics of patient subgroups is a better approach than using overall trial estimates, using individual patient data allows for adjustment for potential confounding factors. These authors caution, however, that metaanalyses of individual patient data are more technically demanding than meta-analysis or meta-regression and that additional statistical methods need to be developed in this area.

Placebo-controlled fracture endpoint trials of at least a 3 -year duration have shown that antiresorptive agents vary widely in their ability to reduce the risk of nonvertebral fractures, regardless of the effect of these agents on BMD. Increases in BMD have been shown in large, randomized, placebo-controlled trials of raloxifene $(n=$ $7705)^{(34)}$ and ibandronate $(n=2946),{ }^{(35)}$ but no significant decrease in the risk of nonvertebral fractures was shown in these trials. Although treatment with alendronate and risedronate leads to significant increases in BMD, the effect of these agents on nonvertebral fractures has varied across studies. $^{(24-26,36-38)}$

Our findings, as well as those of other studies of the relationship between changes in BMD and nonvertebral fracture risk reduction, ${ }^{(8,12)}$ indicate that the magnitude of change in BMD associated with antiresorptive treatment is not a valid surrogate for reduction in the risk of nonvertebral fractures. These data raise important questions about the mechanisms underlying the improvement in bone strength associated with antiresorptive therapy. Increases in $\mathrm{BMD}$, as measured by DXA, are likely caused by increased secondary mineralization (a material property of bone). Recent studies suggest that decreases in bone turnover may be an important contributor to the reductions in vertebral fracture risk associated with antiresorptive therapy. ${ }^{(39,40)}$ Eastell et al. ${ }^{(40)}$ found that changes in bone resorption markers accounted for $>50 \%$ of the reduction in vertebral fracture risk in patients treated with risedronate. Studies in both animal models and humans suggest that it is likely that changes in microarchitecture are also important. ${ }^{(41,42)}$ Thus, it seems that fracture reduction in response to antiresorptive therapy is caused by an interplay of multiple effects and that change in BMD plays only a small role.

The results of our analyses with risedronate, as well as observations from the published literature, ${ }^{(19)}$ indicate that the magnitude of change in BMD associated with risedronate and alendronate treatment does not by itself predict the size of the effect of osteoporosis treatment on nonvertebral fracture risk. These findings indicate that the relative effectiveness of these bisphosphonates on the risk of nonvertebral fracture cannot be inferred on the basis of comparisons of their effects on BMD alone.

\section{ACKNOWLEDGMENTS}

The authors acknowledge Mary G. Royer for help in preparing the manuscript. This work was supported by Procter \& Gamble Pharmaceuticals (Mason, OH, USA) and sanofi-aventis (Bridgewater, NJ, USA).

\section{REFERENCES}

1. NIH Consensus Development Panel on Osteoporosis Prevention, Diagnosis and Therapy 2001 Osteoporosis prevention, diagnosis, and therapy. JAMA 285:785-795.

2. National Osteoporosis Foundation 2005 America's Bone Health: The state of osteoporosis and low bone mass. Available at http://www.nof.org/advocacy/prevalence/. Accessed July 18, 2005.

3. Melton LJ III, Chrischilles EA, Cooper C, Lane AW, Riggs BL 1992 Perspective. How many women have osteoporosis? J Bone Miner Res 7:1005-1010.

4. Food and Drug Administration 2005 Guidelines for preclinical and clinical evaluation of agents used in the prevention or treatment of postmenopausal osteoporosis. Available at http:// www.fda.gov/cder/guidance/osteo.pdf. Accessed July 18, 2005.

5. Delmas PD 2002 Treatment of postmenopausal osteoporosis. Lancet 359:2018-2026.

6. Kanis JA, Oden A, Johnell O, Caulin F, Bone H, Alexandre JM, Abadie E, Lekkerkerker F 2002 Uncertain future of trials in osteoporosis. Osteoporos Int 13:443-449.

7. Khosla S 2003 Surrogates for fracture endpoints in clinical trials. J Bone Miner Res 18:1146-1149.

8. Guyatt GH, Cranney A, Griffith L, Walter S, Krolicki N, Favus M, Rosen C 2002 Summary of meta-analyses of therapies for postmenopausal osteoporosis and the relationship between bone density and fractures. Endocrinol Metab Clin North Am 31:659-679.

9. Hochberg MC, Ross PD, Black D, Cummings SR, Genant HK, Nevitt MC, Barrett-Connor E, Musliner T, Thompson D for the Fracture Intervention Trial Research Group 1999 Larger increases in bone mineral density during alendronate therapy are associated with a lower risk of new vertebral fractures in women with postmenopausal osteoporosis. Arthritis Rheum 42:1246-1254.

10. Li Z, Chines AA, Meredith MP 2004 Statistical validation of surrogate endpoints: Is bone density a valid surrogate for fracture? J Musculoskel Neuron Interact 4:64-74. 
11. Delmas PD, Li Z, Cooper C 2004 The relationship between changes in bone mineral density and fracture risk reduction with anti-resorptive drugs: Some issues with meta-analyses. J Bone Miner Res 19:330-337.

12. Delmas PD, Seeman E 2004 Changes in bone mineral density explain little of the reduction in vertebral or nonvertebral fracture risk with anti-resorptive therapy. Bone 34:599-604.

13. Wasnich RD, Miller PD 2000 Antifracture efficacy of antiresorptive agents are related to changes in bone density. J Clin Endocrinol Metab 85:231-236.

14. Cummings SR, Karpf DB, Harris F, Genant HK, Ensrud K, LaCroix AZ, Black DM 2002 Improvement in spine bone density and reduction in risk of vertebral fractures during treatment with antiresorptive drugs. Am J Med 112:281-289.

15. Wasnich R, Miller PD, Chesnut CH, Huss H, Wilson K, Schimmer RC 2003 Changes in bone mineral density as a predictor of vertebral fracture efficacy with ibandronate: Results from a phase III fracture study. J Bone Miner Res 18:S2;S160.

16. Sarkar S, Mitlak BH, Wong M, Stock JL, Black DM, Harper KD 2002 Relationships between bone mineral density and incident vertebral fracture risk with raloxifene therapy. J Bone Miner Res 17:1-10.

17. Watts NB, Cooper C, Lindsay R, Eastell R, Manhart MD, Barton IP, van Staa TP, Adachi JD 2004 The relationship between changes in bone mineral density and vertebral fracture risk associated with risedronate: Greater increases in bone mineral density do not relate to greater decreases in fracture risk. J Clin Densitom 7:255-261.

18. Sarkar S, Reginster JY, Crans GG, Diez-Perez A, Pinette KV, Delmas PD 2004 Relationship between changes in biochemical markers of bone turnover and BMD to predict vertebral fracture risk. J Bone Miner Res 19:394-401.

19. Bauer DC, Black DM, Garnero P, Hochberg M, Ott S, Orloff J, Thompson DE, Ewing SK, Delmas PD, for the Fracture Intervention Trial Study Group 2004 Change in bone turnover and hip, non-spine, and vertebral fracture in alendronatetreated women: The fracture intervention trial. J Bone Miner Res 19:1250-1258.

20. Blake GM, Wahner HW, Fogelman I 1999 The Evaluation of Osteoporosis: Dual Energy X-Ray Absorptionmetry and Ultrasound in Clinical Practice, 2nd ed. Martin Dunitz Ltd, London, UK.

21. Hochberg MC, Greenspan S, Wasnich RD, Miller P, Thompson DE, Ross PD 2002 Changes in bone density and turnover explain the reductions in incidence of nonvertebral fractures that occur during treatment with antiresorptive agents. J Clin Endocrinol Metab 87:1586-1592.

22. Barton I 2004 The relationship between osteoporotic fracture risk and a surrogate: Apparent discrepancies between analyses based on individual patient data and summary statistics. Pharm Stat 3:205-212.

23. Li Z, Meredith MP 2003 Exploring the relationship between surrogates and clinical outcomes: Analysis of individual patient data vs. meta-regression on group-level summary statistics. J Biopharm Stat 13:777-792.

24. Harris ST, Watts NB, Genant HK, McKeever CD, Hangartner T, Keller M, Chesnut CH III, Brown J, Eriksen EF, Hoseyni MS, Axelrod DW, Miller PD for the Vertebral Efficacy With Risedronate Therapy Study Group (VERT) 1999 Effects of risedronate treatment on vertebral and nonvertebral fractures in women with postmenopausal osteoporosis. A randomized controlled trial. JAMA 282:1344-1352.

25. Reginster J, Minne HW, Sorensen OH, Hooper M, Roux C, Brandi ML, Lund B, Ethgen D, Pack S, Roumagnac I, Eastell $\mathrm{R}$ on behalf of the Vertebral Efficacy With Risedronate Therapy Study Group (VERT) 2000 Randomized trial of the effects of risedronate on vertebral fractures in women with established postmenopausal osteoporosis. Osteoporos Int 11:83-91.

26. McClung MR, Geusens P, Miller PD, Zippel H, Bensen WG, Roux C, Adami S, Fogelman I, Diamond T, Eastell R, Meunier PJ, Reginster JY for the Hip Intervention Program Study Group 2001 Effect of risedronate on the risk of hip fracture in elderly women. N Engl J Med 344:333-340.

27. Li Z, Meredith MP, Hoseyni MS 2001 A method to assess the proportion of treatment effect explained by a surrogate endpoint. Stat Med 20:3175-3188.

28. Freedman LS, Graubard BI, Schatzkin A 1992 Statistical validation of intermediate endpoints for chronic diseases. Stat Med 11:167-178.

29. Looker AC, Wahner HW, Dunn WL, Calvo MS, Harris TB, Heyse SP, Johnston CC Jr, Lindsay R 1998 Updated data on proximal femur bone mineral levels of US adults. Osteoporos Int 8:468-489.

30. Hochberg MC, Miller PD, Wasnich RD, Ross PD, Greenspan S 2004 Letter to the editor. Bone 35:1222-1224.

31. Delmas PD, Seeman E 2004 Response to letter to the editor. Bone 35:1225-1226.

32. Chen C, Wang H, Snapinn SM 2003 Proportion of treatment effect (PTE) explained by a surrogate marker. Stat Med 22:3449-3459.

33. Thompson SG, Higgins JP 2005 Treating individuals 4: Can meta-analysis help target interventions at individuals most likely to benefit? Lancet 365:341-346.

34. Ettinger B, Black DM, Mitlak BH, Knickerbocker RK, Nickelsen T, Genant HK, Christiansen C, Delmas PD, Zanchetta JR, Stakkestad J, Gluer CC, Krueger K, Cohen FJ, Eckert S, Ensrud KE, Avioli LV, Lips P, Cummings SR 1999 Reduction of vertebral fracture risk in postmenopausal women with osteoporosis treated with raloxifene: Results from a 3-year randomized clinical trial. Multiple Outcomes of Raloxifene Evaluation (MORE) Investigators. JAMA 282:637645.

35. Chesnut CH, Skag A, Christiansen C, Recker R, Stakkestad JA, Hoiseth A, Felsenberg D, Huss H, Gilbride J, Schimmer RC, Delmas P 2004 Effects of oral ibandronate administered daily or intermittently on fracture risk in postmenopausal osteoporosis. J Bone Miner Res 19:1241-1249.

36. Black DM, Cummings SR, Karpf DB, Cauley JA, Thompson DE, Nevitt MC, Bauer DC, Genant HK, Haskell WL, Marcus R, Ott SM, Torner JC, Quandt SA, Reiss TF, Ensrud KE 1996 Randomised trial of effect of alendronate on risk of fracture in women with existing vertebral fractures. Fracture Intervention Trial Research Group. Lancet 348:15351541.

37. Cummings SR, Black DM, Thompson DE, Applegate WB, Barrett-Connor E, Musliner TA, Palermo L, Prineas R, Rubin SM, Scott JC, Vogt T, Wallace R, Yates AJ, LaCroix AZ 1998 Effect of alendronate on risk of fracture in women with low bone density but without vertebral fractures: Results from the Fracture Intervention Trial. JAMA 280:2077-2082.

38. Black DM, Thompson DE, Bauer DC, Ensrud K, Musliner T, Hochberg MC, Nevitt MC, Suryawanshi S, Cummings SR 2000 Fracture Intervention Trial. Fracture risk reduction with alendronate in women with osteoporosis: The Fracture Intervention Trial. FIT Research Group. J Clin Endocrinol Metab 85:4118-4124.

39. Bjarnason NH, Sarkar S, Duong T, Mitlak B, Delmas PD, Christiansen C 2001 Six and twelve month changes in bone turnover are related to reduction in vertebral fracture risk during 3 years of raloxifene treatment in postmenopausal osteoporosis. Osteoporos Int 12:922-930.

40. Eastell R, Barton I, Hannon RA, Chines A, Garnero P, Delmas PD 2003 Relationship of early changes in bone resorption 
to the reduction in fracture risk with risedronate. J Bone Miner Res 18:1051-1056.

41. Borah B, Dufresne TE, Chmielewski PA, Johnson TD, Chines A, Manhart MD 2004 Risedronate preserves bone architecture in postmenopausal women with osteoporosis as measured by three-dimensional microcomputed tomography. Bone 34:736746.

42. Jiang Y, Zhao J, Geusens P, Liao EY, Adriaensens P, Gelan J, Azria M, Boonen S, Caulin F, Lynch JA, Ouyang X, Genant HK 2005 Femoral neck trabecular microstructure in ovariectomized ewes treated with calcitonin: MRI microscopic evaluation. J Bone Miner Res 20:125-130.
Address reprint requests to: Nelson B Watts, MD University of Cincinnati Bone Health and Osteoporosis Center 222 Piedmont Avenue, Suite 4300 Cincinnati, $\mathrm{OH} 45219$, USA

E-mail:nelson.watts@uc.edu

Received in original form February 15, 2005; revised form July 25, 2005; accepted August 4, 2005. 